\title{
Oral administration of red rice (Oryza nivara) bran extract reduced weight, visceral fat and liver steatosis amount in obesity male wistar rats (Rattus norvegicus)
}

\author{
Dianika Putri Puspitasari ${ }^{1}$ \\ J. Alex Pangkahila ${ }^{2}$ \\ Ni Nyoman Ayu Dewi ${ }^{3}$
}

\section{Master Program in Biomedical Science, Concentration in Anti-Aging Medicine, Medical Faculty, Udayana University \\ ${ }^{2}$ Department of Andrology and Sexology, Medical Faculty, Udayana University ${ }^{3}$ Department of Biochemistry, Medical Faculty, Udayana University \\ Denpasar, Indonesia}

\section{Cite this article:}

Puspitasari DP, Pangkahila JA, Dewi NNA. Oral administration of red rice (Oryza nivara) bran extract reduced weight, visceral fat and liver steatosis amount in obesity male wistar rats (Rattus norvegicus). Neurologico Spinale Medico Chirurgico. 202I.4(2)63-68. DOI:

I0.36444/nsmc.v4i2.I54

Corresponding author:

Dianika Putri Puspitasari

Master Program in Biomedical Science,

Concentration in Anti-Aging Medicine, Medical Faculty, Udayana University, PB Sudirman Street, Denpasar, Bali, Indonesia

dianika.puspitasari@gmail.com

\begin{abstract}
Background: Nonalcoholic fatty liver disease (NAFLD) is associated with obesity. Red rice (Oryza nivara) bran known to contain polyphenol and antioxidant that might be potential in reducing body weight and visceral fat in obese mice and preventing liver steatosis. This study was aimed to prove the effect of oral administration of red rice bran (Oryza nivara) extract on body weight, visceral fat, and liver steatosis amount in obese male Wistar rats.
\end{abstract}

Method: In this research, the subjects were 36 male obese (Lee index $>0.3$ ) white rats (Rattus norvegicus) Wistar strain, 4-5 months old, divided into two groups. The control group received placebo and the treatment group received $460 \mathrm{mg} / 200 \mathrm{gram}$ red rice bran extract for 5 -weeks. Body weight, visceral fat, and the amount of liver steatosis were observed. Differences between groups in each variable were analyzed.

Results: The weight of the control group and the treatment group was $321.17 \pm 19.04$ grams and $305.72 \pm 12.89$ grams $(\mathrm{p}<0.05)$. The visceral fat weight was $3.15 \pm 0.34$ grams in the control group and $2.99 \pm 0.34$ grams $(p>0.05)$ in the treatment group. Liver steatosis amount was $41 \pm 18$ cells per visual field in the control group, and $21 \pm 12(\mathrm{p}<0.05)$ in the treatment group.

Conclusion: Oral administration of red rice bran extract can reduce body weight and liver steatosis amount in obese Wistar rat. The extract of red rice bran was not have a significant effect in reducing visceral fat.

Keywords: Red rice bran extract, Body weight, Visceral fat, Liver steatosis

\section{Introduction}

Obesity has now become one of the major public health diseases. In the world, the prevalence of obesity has increased almost tripled since $1975 .{ }^{1}$ Obesity is known to cause a decrease in life span and result in cellular and molecular processes that mimic the aging process. Obesity can accelerate the onset of metabolic imbalances that occur in the body. ${ }^{2}$

Nonalcoholic Fatty Liver Disease (NAFLD) is a common aging related liver disease. The decline in liver function that occurs with aging is usually associated with decreased liver blood flow 
and liver volume. Aging is associated with increased in severity and fibrosis progression. Age 70 years or older constitutes the most common proportion of individuals with progressive NAFLD that develop cirrhosis over time. ${ }^{3}$

In NAFLD, obesity results in an increase in visceral fat which then triggers the accumulation of fat in hepatocytes exceeding 5-10\% of liver weight without alcohol consumption and other liver diseases. This accumulation of fat in the liver triggers the condition of steatosis. ${ }^{4}$ Fat deposits in the liver lead to mild inflammation and free radicals that cause liver damage. ${ }^{5}$

The aging process is one of the factors that influence the occurrence of obesity as well as the formation of visceral fat and NAFLD, so the strategy that can be done to improve it is by using the concept of anti aging medicine. One of the theories of aging is free radical theory. To prevent the aging process, antioxidants are used which can overcome free radicals and prolong life. If free radicals can be overcome, the aging process can be inhibited. ${ }^{6}$

Excess fat in obesity releases bioactive substances that trigger inflammation in the body, which is based on the formation of excessive reactive oxygen species (ROS). This process causes oxidative stress which will cause premature aging. ${ }^{7}$ One of the therapeutic approaches in counteracting oxidative stress that occurs in obesity is antioxidant supplementation. ${ }^{8}$ The antioxidant and anti-inflammatory properties of polyphenols are reported to contribute to the improvement of NAFLD. Studies on the liver using experimental animals show the effect of polyphenols on fat tissue function and insulin sensitivity that modulates the development of NAFLD. ${ }^{9}$

Red rice (Oryza nivara) is a plant that can be found easily in Indonesia, and bran processing is gaining popularity in food diversification. Red rice extract has high antioxidant activity due to the high concentration of total phenolic and anthocyanins contained in it. ${ }^{10}$ The red color in the aleurone layer was found to contain polyphenol compounds that are related to genes that produce anthocyanins. ${ }^{11}$

Polyphenol and antioxidant compounds in brown rice bran are expected to reduce body weight and visceral fat in obese mice and prevent oxidative stress and inflammation that triggers liver steatosis. The purpose of this study was to prove the effect of red rice bran extract administration on reducing body weight, visceral fat and liver steatosis in obese male Wistar rats.

\section{Methods}

\section{Ethical consideration}

The protocol was approved by the Animal Ethics Committee of Faculty of Veterinary Medicine, Udayana University (number 50/UN14.2.9/PT.01.04/2020).

\section{Plant material and extraction}

The extract used in this study came from Red rice bran from Cendana varieties obtained from the grain processing factory in Penebel District, Tabanan Regency, Bali Province. The extraction process of red rice bran was carried out in the food analysis laboratory at the Faculty of Agricultural Technology, Udayana University. As many as $4500 \mathrm{gr}$ dry brown rice bran dissolved in $96 \%$ ethanol solvent with $\mathrm{pH}$ 1. The $\mathrm{pH}$ adjustment was obtained by adding $37 \% \mathrm{HCl}$ (Merck) solution to the ethanol solvent until $\mathrm{pH} 1$. The ratio of ingredients and solvents was 1:10 (weight/volume). The solution then was shaken with a shaker for 30 hours at room temperature. The filtrate was obtained through a filtering process using Whatman filter paper No.1. Then it was concentrated in a vacuum rotary evaporator at a temperature of 30 degrees Celsius to obtain a crude extract of brown rice bran. In this study, a dose of $460 \mathrm{mg} / 200 \mathrm{~g}$ BW of rats was used.

\section{Animals model and diet}

In this in vivo experiment, 36 white male rats (Rattus norvegicus), male, healthy, aged 4-5 months was used. The rats were given high-calorie feed and 70\% fructose HCD ad libitum for 5 months. High calorie feed was a standard food enriched with corn and lard. After 5 weeks, the rats became obese with a Lee index $>0.3$. Then the rats were randomly divided into 2 groups (18 rats each) and the food of the two groups of rats was changed to standard food. Standard food contained $14 \%$ water, $14 \%$ ash, $16 \%$ rough protein $3 \%$ fat, $8 \%$ fiber, $2,75 \%$ calcium and $0,6 \%$ total phosphor (BRS3-593). The control group was given standard food and placebo (aquades) $2 \mathrm{ml} /$ day for 5 weeks while the treatment group was given standard food and brown rice bran extract $460 \mathrm{mg} / 200 \mathrm{~g}$ BW for 5 weeks.

\section{Measurement of body weight}

After 5 weeks, the next day the two groups were weighed using the Sartorius scale. Body weight was recorded in gram.

\section{Measurement of visceral fat}

All surgery was performed on all groups to remove the visceral fat in abdominal area and liver. Before surgery, the mice were euthanized with ketamine xylazine, a ratio of 1: 1 with a dose of $0.3 \mathrm{cc}$ injected intracardially. Visceral abdominal fat was taken from fat found in the intraperitoneal area, including omental and epididimal fat. The visceral fat was weighed using a Sartorius scale.

\section{Identification of liver steatosis}

Liver resection was performed, then the cut was washed and preserved with formalin prior to analysis. Liver preparations were 
made and stained with Hematoxilin Eosin dye. Observation of liver tissue preparations was carried out with the help of an Olympus CX21 microscope connected to Optilab and a computer equipped with Optilab Image Raster 3 software. Observations began with a 100x objective lens magnification to observe the entire visual field, to determine the area to be observed, namely the centrilobular area. around the central vein of the hepatic lobule. Then the liver histological preparations were observed with an objective lens magnification of 400x and in five different visual field. From each visual field, liver steatosis amount were calculated randomly. Steatosis was calculated from the number of liver cells (hepatocytes) whose cytoplasm contains fat globule in the form of microvesicular and macrovesicular vacuoles in each field of view. Steatosis from 5 fields of view was averaged.

\section{Statistical analysis}

Data was described as mean, standard deviation, median, minimum value, and maximum value. The differences between groups were examined for statistical significance using the independent $\mathrm{T}$ test. The criterion for significance was $\mathrm{p}<0.05$.

\section{Results}

The red rice bran extract used in this study contained a total anthocyanin content of $5.45 \mathrm{mg} / 100 \mathrm{~g}$, a total phenol of $743.51 \mathrm{mg} / 100$ $\mathrm{g}$, an antioxidant activity of $92.9 \%$, and an IC50 of $44.74 \mathrm{mg} / \mathrm{L} .{ }^{11}$ The body weight of the control group was $321.17 \pm 19.04$ grams, which was significantly lower than the treatment group $305.72 \pm 12.89$ grams. The mean weight of visceral fat in the control group was $3.15 \pm 0.34$ grams, while the mean weight of visceral fat in the treatment group was $2.99 \pm$ 0.34 grams. The weight of visceral fat in the treatment group was lower than the control group, but the comparative test results of the mean weight of visceral fat between the control and treatment groups showed insignificant results $(\mathrm{p}>0.05)$.

Microvesicular liver steatosis was obtained in both the control and treatment groups with the nucleus not pushed to the edge (Figure 1). There was no macrovesicular hepatic steatosis, ballooning with Mallory body or fibrosis in both the treatment and control groups.

The mean number of liver steatosis in the control group was $41 \pm 18$ cells/visual fields while the mean number of liver steatosis in the treatment group was $21 \pm 12$ cells/visual fields. The comparative test results of the mean amount of liver steatosis between control and treatment groups showed significant results $(\mathrm{p}<0.05)($ Table 1$)$.
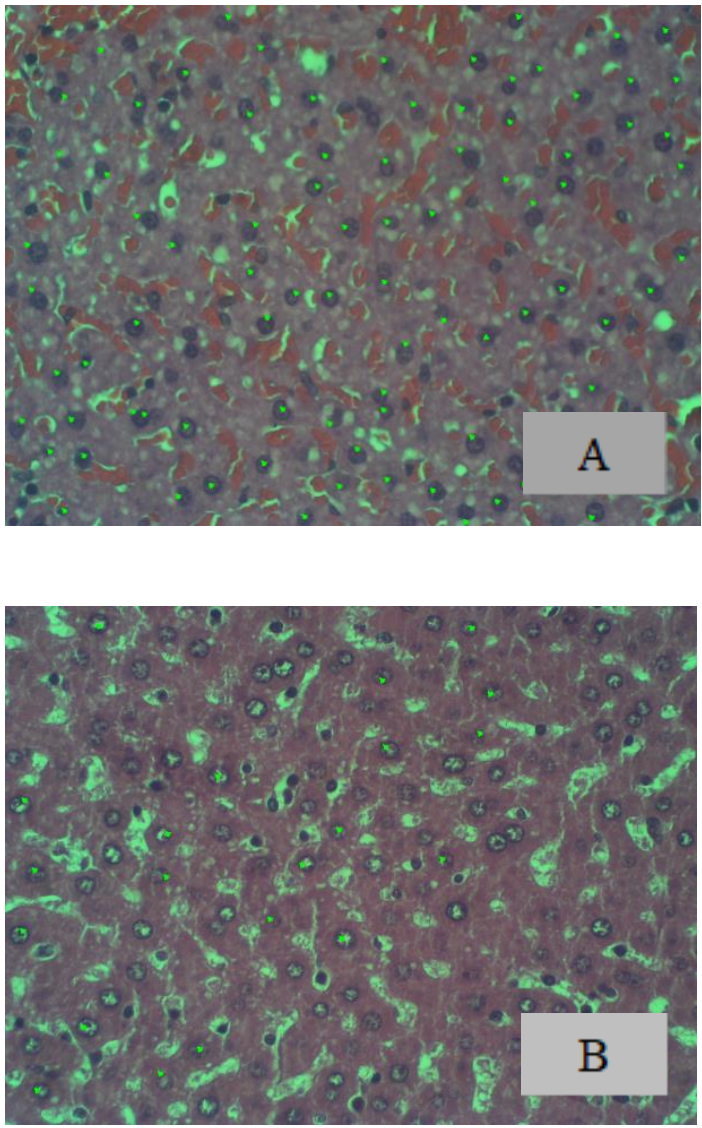

Figure 1. The comparison of liver histopathology in the control group (A) and the treatment group $(B)$ with more steatosis in the control group than the treatment group. Green spots show liver cells with microvesicular steatosis (Hematoxilin- Eosin Staining; 400x magnification)

Table 1. Analysis of body weight, visceral fat and total liver steatosis

\begin{tabular}{llccc}
\hline \multicolumn{1}{c}{ Variable } & Group & f & Mean \pm SD & p value \\
& & & & \\
\hline Body Weight & Control & 18 & $321.17 \pm 19.04$ & 0.007 \\
(gram) & Treatment & 18 & $305.72 \pm 12.89$ & \\
& & & & \\
Visceral Fat & Control & 18 & $3.15 \pm 0.34$ & 0.166 \\
(gram) & Treatment & 18 & $2.99 \pm 0.34$ & \\
& & & & \\
Liver Steatosis & Control & 18 & $41 \pm 18$ & 0.001 \\
(cells/ visual field) & Treatment & 18 & $21 \pm 12$ & \\
\hline
\end{tabular}

\section{Discussion}

The use of polyphenol-rich functional foods such as rice with pigments can act as an alternative complementary therapy against obesity. Several studies have shown that giving polyphenol supplementation in experimental animals can modulate mycobiota, 
regulate blood sugar, insulin and triglycerides so that they can lose weight by targeting inflammatory pathways and free radicals at the transcription and physiological level. ${ }^{12}$ In vitro studies have shown that black rice extract is known to reduce fat accumulation in mesenchymal stem cells (MSC's) C3H101/2 by suppressing adipocyte differentiation through downregulation of key transcription factors peroxisome proliferator activated-receptor $\gamma$, CCAAT-Enhancer Binding Protein-a and CCAAT-Enhancer Protein- $\delta$ binding. ${ }^{13}$

The administration of brown rice bran extract to obese male Wistar rats who were induced with a high-calorie diet and $70 \%$ high carbohydrate diet fructose resulted in a significantly lower weight loss than body weight in the control group. Bran supplementation not only has the benefit of preventing metabolic and biochemical changes related to obesity, but can prevent changes in adipocyte structure and reduce pro-inflammation. ${ }^{14}$ Polyphenol extract supplementation from bran has anti-inflammatory potential by reducing the production of proinflammatory cytokines TNF-a, IL-6 and iNOS in fat tissue of obese Zucker rats. ${ }^{14}$ Justo et al., (2015) found a decrease in MDA, which is a free radical marker, by administering rice bran extract. ${ }^{15}$ The alcohol content of triterpenes and sterols in bran and oryzanol can reduce fat metabolic activity, thereby reducing fatty acid synthesis in the liver and reducing body weight in studies on animal models with obesity. ${ }^{15}$

Yang et al., (2012) found that protein in rice can reduce body weight and adiposity through modification of triglyceride metabolism. ${ }^{16}$ This anti-obesity potential is induced by protein in rice through upregulation of lipolysis and downregulation of lipogenesis. You et al., (2018) and Singh et al., (2020) found that brown rice bran extract has the potential to inhibit pancreatic lipase. ${ }^{17}$ Inhibition of fat absorption is the main modulator responsible for reducing triglycerides. Brown rice bran was found to have the potential to reduce triglycerides as well as administration of simvastatin. ${ }^{18}$

The comparative test results showed insignificant results $(p>0.05)$, although the weight of visceral fat of Wistar rats given brown rice bran extract was lower than the weight of Visceral fat in the control group. Another study also found an improvement in the circumference of the visceral fat area in mice with dyslipidemia given bran extract, but it was not significant $(\mathrm{p}=0.09) .{ }^{19,20}$

Although it did not provide a significant reduction in visceral fat weight, administration of bran extract was able to modulate and influence cytokine production and on histological examination of fat tissue found a change in the characteristics and distribution patterns of adipocyte size into smaller cells. ${ }^{20}$ Polyphenols in bran extract were found to suppress proinflammatory cytokines and inhibit mitogen- activated protein kinase (MAPK) pathways in macrophages so that reduce adipocyte size and decrease oxidative stress as measured by malondialdehyde (MDA). ${ }^{12,21}$

In diet-induced obesity, the AdipoChaser mouse, a mouse model that shows in vivo adipogenesis, has shown a hypertrophic visceral fat image at four weeks, while tissue hyperplasia occurs within two months. ${ }^{22}$ In this study, with a high-calorie and $70 \%$ fructose diet for weeks, it was possible to have hypertrophy of visceral fat and adipocyte tissue only.

The liver plays a key role in maintaining liver fat homeostasis and energy balance through several metabolic pathways (eg, de novo lipogenesis, fatty acid uptake, fatty acid oxidation, and triacylglycerol (TG) export). An imbalance between these processes can lead to an abnormal accumulation of liver lipids known as NAFLD. ${ }^{23}$ Steatosis results from the hepatocellular accumulation of cytoplasmic macrovesicular lipid droplets that replace the nucleus. Lipid droplets are the nucleus of neutral lipids (triglycerides) surrounded by a single phospholipid membrane. ${ }^{24}$

On the histopathological examination of the liver of obese rats induced by a diet high in calories and $70 \%$ fructose, it was found that microvesicular steatosis with hepatocytes that appeared foamy appeared in azonal distribution in both the treatment and control groups. The amount of microvesicular steatosis of Wistar rats given red rice bran extract was significantly lower than body weight in the control group.

These results suggest that rice bran may have an inhibitory effect on lipid accumulation in the liver. The provision of rice bran tends to reduce the accumulation of lipids in the liver because of its main bioactive compound, $\gamma$-oryzanol. ${ }^{25}$ The decrease of microvesicular steatosis with the administration of red rice bran extract was also possible due to the improvement of liver fat accumulation through sterol regulatory element binding proteins-1 (SREBP-1) regulation, AMPK expression and 3-Hydroxy-3-Methylglutaryl-CoA Reductase (HMGCR) activity in obese rats. Rice bran extract also attenuates the damaging effects of oxidative stress by reducing lipid peroxidation and expression of $N F \kappa \beta$ in the liver. ${ }^{26}$ Rice bran supplementation can also improve adiposity by partially reducing the increase in diacylglycerol (DG) and TG in diet-induced obese rats. ${ }^{25}$

Red rice bran contains anthocyanins which also have a role in improving NAFLD. Fan et al., (2019) showed that giving anthocyanins can improve liver function in NAFLD rats, regulate blood lipids, reduce liver fat accumulation, and regulate lipid metabolism. ${ }^{27}$ 
In this study, a high-calorie diet and HCD with $70 \%$ fructose for 5 weeks was expected to induce adipogenesis in mice. However, this obese induced diet given 5 weeks was only triggered changes in the form of adipocyte hypertrophy so that the weight gain was not as big as when there was adipocyte hyperplasia. The effect of brown rice bran extract in reducing visceral fat weight was found to be insignificant in this study. The longer induction time, which is 2 months or more, can trigger hyperplasia with an increase in the weight of adipose tissue so that the effect of giving the extract on the weight of visceral fat can be more visible.

Visceral fat with hypertrophied adipocytes was infiltrated by macrophages that triggered the release of pro-inflammatory cytokines that can lead to liver damage. Polyphenols such as those contained in red rice bran extract have the potential to reduce proinflammatory cytokines and reduce the size of adipocytes. ${ }^{28}$ This mechanism cannot yet be explained in this study. Measurement of adipocyte size on visceral fat can be another parameter that might show the efficacy of red rice bran extract to reduce visceral fat.

This study showed that red rice bran supplementation provided a reduction in body weight and amount of hepatic steatosis in obese rats induced by a high-calorie diet and 70\% fructose HCD. However, the mechanism behind it cannot be explained in this study. The calculation of the remaining feed can provide an idea whether the weight loss due to the administration of red rice bran extract also occurs through a decrease in appetite. The pattern of food consumption became a weakness of the study because there was no measurement of the remaining feed consumed. Further research can be conducted to determine which pathway was involved in weight loss and reduction in the amount of liver steatosis by administering red rice bran extract.

\section{Conclusion}

In conclusion, the present study demonstrates that oral administration of red rice bran extract (Oryza nivara) reduced body weight and liver steatosis mass in obese male Wistar rats with obesity. Visceral fat mass was reduced but insignificant. Further research is needed to assess the effect of giving red rice bran extract on the size of adipocyte cells in visceral fat. Extending the induction time of obesity through diet can be the other option to obtain hyperplasia in visceral fat's adipose tissue so that the efficacy or red rice bran extract can be more visible.

The mechanism of weight loss and reduction in the amount of liver steatosis by administering red rice bran extract was not examined in this study. Measuring the remaining feed in Wistar rats to determine the correlation between weight loss and the potential to control appetite by giving brown rice bran extract can be obtained in further study.

\section{References}

1. WHO. Obesity and overweight. [Online]. https://www.who.int/news-room/fact-sheets/detail/obesity-andoverweight. 2018. Cited 2020 February.

2. Salvestrini V, Sell C, Lorenzini A. Obesity may accelerate the aging process. Front Endocrinol (Lausanne). 2019;10:266. DOI: 10.3389/fendo.2019.00266

3. Bertolotti M, Lonardo A, Mussi C, et al. Nonalcoholic fatty liver disease and aging: Epidemiology to management. World $J$ Gastroenterol. 2014;20(39):14185-14204. DOI: 10.3748/wjg.v20.i39.14185

4. Chalasani N, Younossi Z, Lavine JE, et al. The diagnosis and management of non-alcoholic fatty liver disease: Practice guideline by the American Association for the Study of Liver Diseases, American College of Gastroenterology, and the American Gastroenterological Association. Hepatology. 2012;55(6):20052023. DOI: $10.1002 /$ hep. 25762

5. Verrijken A, Francque S, Van Gaal L. The role of visceral adipose tissue in the pathogenesis of non-alcoholic fatty liver disease. Euro Endocrinol. 2011;7(2):96-103. DOI: 10.17925/EE.2011.07.02.96

6. Sadowska-Bartosz I, Bartosz G. Effect of antioxidants supplementation on aging and longevity. Biomed Res Int. 2014;404680. DOI: 10.1155/2014/404680

7. Fernández-Sánchez A, Madrigal-Santillán E, Bautista M, et al. Inflammation, oxidative stress, and obesity. Int J Mol Sci. 2011;12:3117-3132. DOI: 10.3390/ijms12053117

8. Hidayat M, Soeng S, Prahastuti S, et al. Aktivitas antioksidan dan antitrigliserida ekstrak tunggal kedelai, daun jati Belanda serta kombinasinya. Bionatura-Jurnal Ilmu-Ilmu Hayati Dan Fisik. 2014;16(2):89-94.

9. Rodriguez-Ramiro D, Vauzour A, Minihane M. Polyphenols and non-alcoholic fatty liver disease: Impact and mechanisms. Proceedings of the Nutrition Society. 2016;75(1):47-60. DOI: 10.1017/S0029665115004218

10. Widarta IWR, Arnata IW. Stabilitas aktivitas antioksidan ekstrak bekatul beras merah terhadap oksidator dan pemanasan pada berbagai ph [Stability of antioxidant activity of red rice bran extract subjected to oxidator and heating in various $\mathrm{pH}$ ]. Jurnal Teknologi 
Dan Industri Pangan. 2014;25(2):193-199. DOI: 10.6066/jtip.2014.25.2.193

11. Muntana N, Prasong S. Study on total phenolic contents and their antioxidant activities of Thai white, red and black rice bran extracts. Pakistan $J$ of Bio Sci. 2010;13(4):170-74. DOI: 10.3923/pjbs.2010.170.174

12. Callcott ET, Blanchard CL, Oli P, et al. Pigmented rice-derived phenolic compounds reduce biomarkers of oxidative stress and inflammation in human umbilical vein endothelial cells. Mol Nutr Food Res. 2018;62:1800840. DOI: 10.1002/mnfr.201800840

13. Kim SY, Kim YJ, An YJ, et al. Black rice (Oryza sativa, heukmi) extracts stimulate osteogenesis but inhibit adipogenesis in mesenchymal C3H10T1/2 cells. J Food Biochem. 2016;40:235247.

14. Justo ML, Claro C, Zeyda M, et al. Rice bran prevents high fat dietinduced inflammation. Eur J Nutr. 2015;55(6):2011-2019. DOI: 10.1007/s00394-015-1015-x

15. Okahara F, Suzuki J, Hashizume K, et al. Triterpene alcohols and sterols from rice bran reduce postprandial hyperglycemia in rodents and humans. Mol Nutr Food Res. 2016;60(7):1-11. DOI: 10.1002/mnfr.201500897

16. Yang C, Johnson MP, Schorpp KM, et al. Young adult risk factors for cancer: Obesity, inflammation, and sociobehavioral mechanisms. Am J Prev Med. 2013;53(3S1):S21-S29. DOI: 10.1016/j.amepre.2017.04.025

17. Singh M, Thrimawithana T, Shukla R., et al. Managing obesity through natural polyphenols: A review. Future Foods. 2020;12(6):100002. DOI: 10.1016/j.fufo.2020.100002

18. Kurniawati DC. Pemberian ekstrak bekatul beras merah (Oryza nivara) sama efektif dengan simvastatin dalam memperbaiki kadar kolesterol total dan trigliserida daripada tikus Wistar jantan (Rattus norvegicus) dislipidemia [Thesis]. Denpasar: Universitas Udayana; 2016.

19. Ito Y, Nakashima Y, Matsuoka S. Rice bran extract containing acylated steryl glucoside fraction decreases elevated blood LDL cholesterol level in obese Japanese men. $J$ of Med Invest. 2015;62(1-2):80-84. DOI: 10.2152/jmi.62.80

20. Candiracci M, Justo ML, Castano A, et al. 2014. Rice bran enzymatic extract-supplemented diets modulate adipose tissue inflammation markers in Zucker rats. Nutrition. 2014;30(4):466472. DOI: 10.1016/j.nut.2013.09.016

21. Munkong N, Hansakul P, Yoysungnoen B, et al. Vasoprotective effects of rice bran water extract on rats fed with high-fat diet. Asian Pac $J$ of Trop Bio. 2016;6(9):778-784. DOI: 10.1016/j.apjtb.2016.07.009

22. Kim SM, Lun M, Wang M, et al. Loss of white adipose hyperplastic potential is associated with enhanced susceptibility to insulin resistance. Cell Metab. 2014;20:1049-1058. DOI: 10.1016/j.cmet.2014.10.010

23. Yaligar J, Gopalan V, Kiat OW, et al. Evaluation of dietary effects on hepatic lipids in high fat and placebo diet fed rats by in vivo MRS and LC-MS techniques. PLoS ONE. 2014;9(3): e91436. DOI: 10.1371/journal.pone.0091436

24. Carr RM, Ahima RS. Pathophysiology of lipid droplet proteins in liver diseases. Exp Cell Res. 2016;340(2):187-192. DOI: 10.1016/j.yexcr.2015.10.021

25. Somnuk S, Komindr S, Munkong N, et al. Protective effects of rice bran water extract (RBE) on hepatic fat metabolism and oxidative damage in rats fed a high-fat diet. Med Assoc Thai. 2017;100(6):224

26. Yang J, Fernández-Galilea M, Martínez-Fernández L, et al. Oxidative stress and non-alcoholic fatty liver disease: Effects of omega-3 fatty acid supplementation. Nutrients. 2019;11(4):1-37. DOI: $10.3390 /$ nu11040872

27. Fan M, Choi Y, Tang Y, et al. Efficacy and mechanism of polymerized anthocyanin from grape-skin extract on high-fat-dietinduced nonalcoholic fatty liver disease. Nutrients. 2019; 11(11):2586. DOI: 10.3390/nu11112586

28. Callcott ET, Santhakumar AB, Luo J, et al. Therapeutic potential of rice-derived polyphenols on obesity-related oxidative stress and inflammation. $J$ of App Biomed. 2018;16(4):255-262. DOI: 10.1016/j.jab.2018.03.001 